\title{
Construction of a Versatile High Precision Ambient Ionization Source for Direct Analysis and Imaging
}

\author{
Jason S. Sampson, Adam M. Hawkridge, and David C. Muddiman \\ W. M. Keck FT-ICR Mass Spectrometry Laboratory, Department of Chemistry, North Carolina State \\ University, Raleigh, North Carolina, USA
}

The design and construction of a high precision ambient ionization source matrix-assisted laser desorption electrospray ionization (MALDESI) are described in full detail, including a complete parts list. The computer controlled high precision motion control system and high repetition rate Explorer laser are demonstrated during MALDESI-FT-ICR analysis of peptides and proteins ranging from 1 to $17 \mathrm{kDa}$. The high stability ionization source platform described herein demonstrates both the advantages of the new MALDESI source and versatility for application to numerous desorption and ionization techniques. (J Am Soc Mass Spectrom $2008,19,1527-1534)(C 2008$ American Society for Mass Spectrometry

$\mathrm{T}$ The introduction and development of hybrid ambient ionization sources such as laser desorption atmospheric pressure ionization (LDAPI) [1, 2], fused droplet electrospray ionization/extraction electrospray (FD-ESI, EESI) [3, 4], direct analysis in real time (DART) [5], desorption electrospray ionization (DESI) [6], electrospray assisted laser desorption ionization (ELDI) [7-11], matrix-assisted laser desorption electrospray ionization (MALDESI) [12, 13], and infrared laser desorption electrospray ionization [14, 15] have advanced the capabilities of mass spectrometry. MALDESI, for example, is a pulsed ionization source that holds promise in areas ranging from top-down proteomics, tissue imaging, and ionization mechanism elucidation. The pulsed nature of MALDESI combined with its ability to generate multiply-charged ions are characteristics that are particularly well suited for Fourier transform ion cyclotron resonance (FT-ICR) and Orbitrap (LTQ-Orbi) mass spectrometry due to the inverse relationship of frequency to $\mathrm{m} / \mathrm{z}$ and $\sqrt{ }(\mathrm{m} / \mathrm{z})$, respectively. The consequence of this relationship is high resolving power, $<3 \mathrm{ppm}$ mass measurement accuracy, and amenability to a multitude of tandem MS/MS techniques for bottom-up and top-down proteomics (e.g., CID, ETD, ECD, SORI, and IRMPD) [16-18]. Many of these MS/MS techniques in FT-ICR and Orbitrap instruments would benefit from a pulsed ionization source where intact proteins and polypeptides with complex post-translational modifications could be carefully interrogated rather than the typical "continuous" ionization encountered during a LC-

Address reprint requests to Dr. D. C. Muddiman, W. M. Keck FT-ICR Mass Spectrometry Laboratory, Department of Chemistry, North Carolina State University, Raleigh, NC 27695, USA. E-mail: david_muddiman@ncsu.edu
MS/MS analysis where peak widths (i.e., analysis times) are about 10 to $30 \mathrm{~s}$.

The advancement and acceptance of MALDESI and related hybrid ionization techniques are critically dependent on the widespread dissemination of detailed source designs such that results can be reproduced and improved in a variety of laboratories. Furthermore, there are certainly unanticipated potential applications that could benefit from novel or improved source designs. Herein, we provide a detailed description and characterization of the third version of the MALDESI source utilized in this laboratory. The further improvement to this design both within our laboratory as well as other laboratories should enable MALDESI and related hybrid ambient ionization sources to mature to a level of analytical robustness now widely enjoyed for ESI and MALDI.

\section{Experimental}

\section{Materials}

Bradykinin, angiotensin I, melittin, glucagon, bovine ubiquitin, lysozyme, myoglobin, and 2,5-dihydroxybenzoic acid were purchased from Sigma-Aldrich (St. Louis, MO) and used without further purification. HPLC-grade acetonitrile and high purity water were purchased from Burdick and Jackson (Muskegon, MI). The electrospray solution was prepared by mixing acetonitrile and water 1:1 (vol:vol). The organic matrix solution was prepared by dissolving $150 \mathrm{mg}$ DHB into $1 \mathrm{~mL}$ of the electrospray solution. All samples were prepared from $200 \mu \mathrm{M}$ stock solutions and mixed 1:1 (vol:vol) with the matrix solution. Sample spots of $0.8 \mu \mathrm{L}$ of the analyte matrix solution were deposited for each sample, equivalent to $\sim 80 \mathrm{pmol}$ analyte per spot. 


\section{Profilometery Measurements}

A Tencor Alpha Step profilometer (5 $\mathrm{nm}$ resolution) was used to measure the diameter of the laser ablation crater in a gold coated QCM electrode. The distance was measured across the width of the laser ablation craters with three repeats at a scan speed of $50 \mu \mathrm{m} / \mathrm{s}$. The QCM electrode (International Crystal Manufacturing, Oklahoma City, OK) consisted of 10 $\mathrm{MHz} \mathrm{A} / \mathrm{T}$ cut quartz crystal with a $1000 \AA$ gold layer coated on a chromium base layer.

\section{MALDESI-LTQ-FT Mass Spectrometry}

MALDESI mass spectra were obtained using a hybrid LTQ-FT Ultra mass spectrometer (Thermo Electron Inc., San Jose, CA and Bremen, Germany) equipped with an actively-shielded $7 \mathrm{~T}$ superconducting magnet (Oxford Instruments, Concord, MA). The MALDESI source (Figure 1) was placed in front of the LTQ-FT fitted with a modified extended ion transfer capillary (part no. 54). Solvent was electrosprayed at $2.8 \mathrm{kV}$ through a $75 \mu \mathrm{m}$ i.d. fused silica capillary (part no. 40) with a $30 \mu \mathrm{m}$ fused silica tapered PicoTip (part no. 44) using a Harvard PHD-2000 syringe pump (part no. 28) at a flow rate of $400 \mathrm{~nL} / \mathrm{min}$. The analyte was laser desorbed from each sample spot actively-dried [19] onto a stainless steel sample target (part no. 36) located directly below and between the ESI emitter and the ion transfer capillary. The stainless steel sample target was biased at $300 \mathrm{~V}$. Each mass spectrum was single-acquisition with resolving power at $400 \mathrm{~m} / \mathrm{z}$ set to $200,000_{\mathrm{FWHM}}$ and the AGC is set to $1 \times 10^{6}$.

\section{Source Design}

\section{MALDESI Source Design and Construction}

A new version of the MALDESI source was constructed based in part on the previous source design [12, 13]. A photo of the new source is shown in Figure 1 with major parts indicated. A complete parts list, grouped by manufacturer, is included in Table 1 , with specifications for custom fabricated parts described in Table 2. A schematic of the ionization source labeled by part number is included in the Supplemental Material (Figure S1, which can be found in the electronic version of this article). The manual linear XYZ sample positioning stages were replaced with computer controlled motorized sample positioning stages (parts no. 2-5) and control unit (part no. 6) for precise sample positioning during analysis. The high speed long travel translational stages (parts no. 2,3) allow for interrogation of samples across the full length and width of a standard MALDI target (part no. 36). Custom translation programming was accomplished using the supplied software (Newport, ESP); enabling one touch program execution for whole sample spot analysis, [a diagram of the ablation path is shown in the Supplemental Material (Figure S2)], as well as allowing the user to operate the source remotely. The position control can be actuated linearly without program execution for spot to spot analysis, as typically performed in MALDI. The high precision $(0.035 \mu \mathrm{m}$ resolution, $100 \mathrm{~nm}$ increments) of the positioning system enables accurate repeatable $( \pm$ $600 \mathrm{~nm}$, bidirectional) positioning amenable to applications requiring a high degree of positioning control (e.g., tissue imaging).

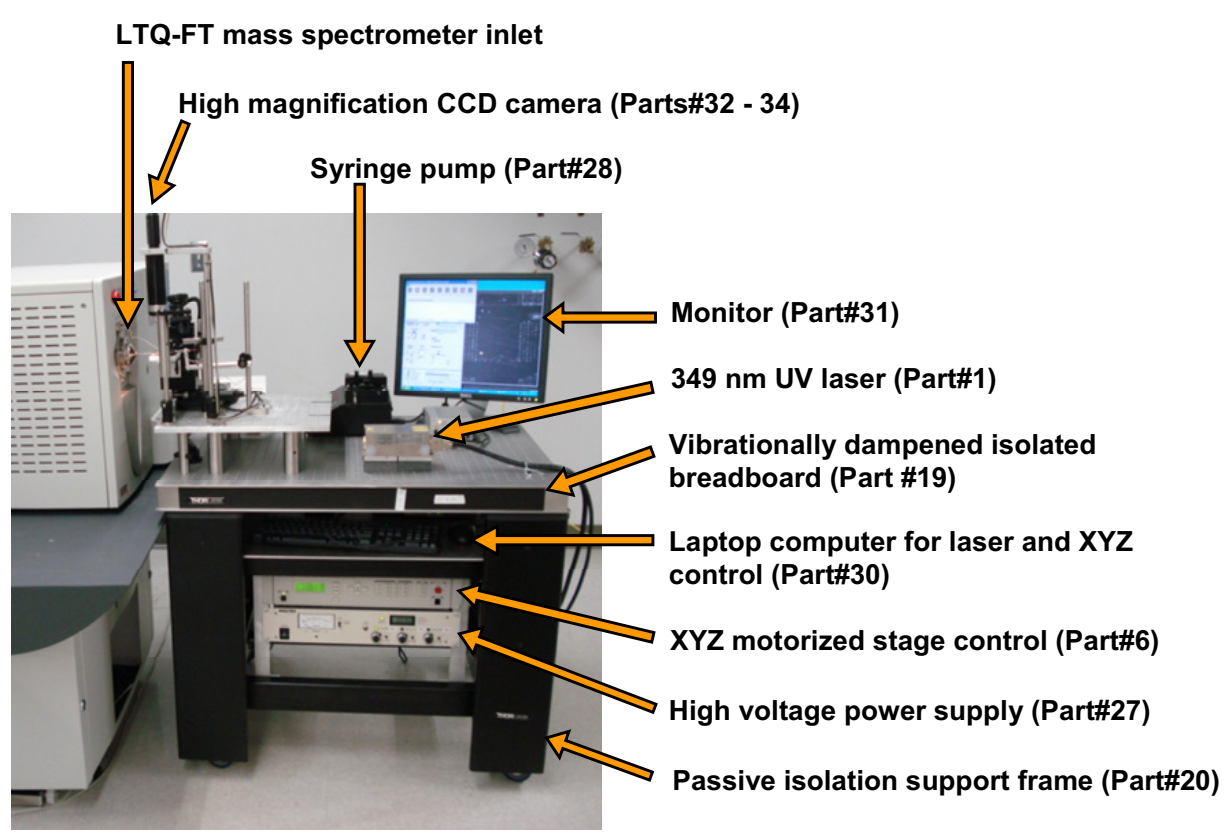

Figure 1. Photograph of the new MALDESI ionization source coupled to a LTQ-FT mass spectrometer with major parts indicated and part numbers that correspond to those listed in Table 1. 
Table 1. MALDESI parts list

\begin{tabular}{|c|c|c|c|c|}
\hline Part no. & Description & Distributor & Stock no. & Quantity \\
\hline 1 & Explorer Q-Switched DPSS Laser & Newport (Irvine, CA) & EXPL-349-120-1KE & 1 \\
\hline 2 & High performance low profile linear stage & Newport (Irvine, CA) & 436 & 3 \\
\hline 3 & Motorized actuator ( $\mathrm{x}$ and $\mathrm{y}$ axes) & Newport (Irvine, CA) & LTA-HS & 2 \\
\hline 4 & Vernier Micrometer (z axis) & Newport (Irvine, CA) & SM-50 & 1 \\
\hline 5 & Angle bracket $\left(90^{\circ}\right)$ & Newport (Irvine, CA) & $360-90$ & 1 \\
\hline 6 & 2 Axis motion controller/driver & Newport (Irvine, CA) & ESP300-11N1N1 & 1 \\
\hline 7 & 19 in. rack mount brackets (ESP300) & Newport (Irvine, CA) & ESP300-R & 1 \\
\hline 8 & Slotted base & Newport (Irvine, CA) & B-05A & 3 \\
\hline 9 & 2 in. post holder & Newport (Irvine, CA) & VPH-2 & 3 \\
\hline 10 & 2 in. ss post & Newport (Irvine, CA) & SP-2 & 1 \\
\hline 11 & 4 in. ss post & Newport (Irvine, CA) & $\mathrm{SP}-4$ & 1 \\
\hline 12 & 6 in. ss post & Newport (Irvine, CA) & SP-6 & 2 \\
\hline 13 & 12 in. ss post & Newport (Irvine, CA) & SP-12 & 2 \\
\hline 14 & Right angle post connector & Newport (Irvine, CA) & CA-1 & 1 \\
\hline 15 & Adjustable angle post connector & Newport (Irvine, CA) & CA-2 & 1 \\
\hline 16 & $1 \mathrm{in.} \mathrm{lens} \mathrm{mount}$ & Newport (Irvine, CA) & $\mathrm{LH}-1$ & 1 \\
\hline 17 & UV fused silica plano convex lens AR10 & Newport (Irvine, CA) & SPX017 + AR.10 & 1 \\
\hline 18 & UV enhanced aluminum mirror & Newport (Irvine, CA) & 10D20AL.2 & 2 \\
\hline 19 & Performance plus breadboard & Thorlabs (Newton, NJ) & PBI11111 & 1 \\
\hline 20 & Passive support frame $\left(27.5^{\prime \prime} \mathrm{H} \times 36^{\prime \prime} \mathrm{L} \times 30^{\prime \prime} \mathrm{W}\right)$ & Thorlabs (Newton, NJ) & PFP51505 & 1 \\
\hline 21 & Periscope assembly & Thorlabs (Newton, NJ) & RS99 & 1 \\
\hline 22 & 4 in. stainless steel post & Thorlabs (Newton, NJ) & RS4 & 1 \\
\hline 23 & 4 in. mounting post & Thorlabs (Newton, NJ) & P4 & 4 \\
\hline 24 & Swivel casters ( 3 in.) & Grainger & $1 \mathrm{G} 196$ & 4 \\
\hline 25 & Caster brake kit & Grainger & $4 \times 698$ & 4 \\
\hline 26 & Power strip (6 plug) & Grainger & $6 \times 953$ & 2 \\
\hline 27 & DC power supply & Analytica of Branford & 103510 & 1 \\
\hline 28 & PHD 2000 syringe pump & Harvard Apparatus & $70-2000$ & 1 \\
\hline 29 & Fiber-Lite Light source & Dolan Jenner & MI-150 & 1 \\
\hline 30 & Dell laptop computer (Pentium M, $1.4 \mathrm{GHz}$ ) & Dell & N/A & 1 \\
\hline 31 & Dell 19 in. monitor & Dell & $\mathrm{N} / \mathrm{A}$ & 1 \\
\hline 32 & CCD camera & Hitachi & KP-M1AN & 1 \\
\hline 33 & Leica optical amplifier & Vashaw Scientific & 312996 & 1 \\
\hline 34 & Leica monozoom 7 & $\mathrm{~N} / \mathrm{A}$ & $\mathrm{N} / \mathrm{A}$ & 1 \\
\hline 35 & Happauge Win-TV USB-2 & Circuit City & $\mathrm{N} / \mathrm{A}$ & 1 \\
\hline 36 & SS 192 well MALDI plate & Applied Biosystems & 4333375 & 1 \\
\hline 37 & RS232 to USB converter & Tiger Direct & $\mathrm{N} / \mathrm{A}$ & 1 \\
\hline 38 & High Voltage wire (5kV, 2 pcs. 12 in., 24 in.) & N/A & $\mathrm{N} / \mathrm{A}$ & 1 \\
\hline 39 & LTO high voltage plug & Connectronics Corp. & $10334-02$ & 1 \\
\hline 40 & 24 in. fused silica capillary (75 um i.d.) & Polymicro Technologies & 2000019 & 1 \\
\hline 41 & Stainless steel union & Valco Instrument Co. & ZUIXC & 1 \\
\hline 42 & Syringe adapter & Valco Instrument Co. & VISF-2 & 1 \\
\hline 43 & PEEK tubing sleeve orange $0.062 \times 0.016$ & Upchurch Scientific & $\mathrm{F}-230$ & 2 \\
\hline 44 & Silica tip (30 um i.d. tapered) & New Objective Inc. & FS360-75-30-N-20 & 1 \\
\hline 45 & Hamilton gas tight syringe $100 \mathrm{uL}$ & Fisher Scientific & $14-813-138$ & 1 \\
\hline 46 & Breadboard & Fabricated in house & N/A & 1 \\
\hline 47 & Camera support bracket & Fabricated in house & $\mathrm{N} / \mathrm{A}$ & 1 \\
\hline 48 & Teflon ESI holder & Fabricated in house & $\mathrm{N} / \mathrm{A}$ & 1 \\
\hline 49 & Sample target high voltage clip & Fabricated in house & $\mathrm{N} / \mathrm{A}$ & 1 \\
\hline 50 & 19 in. rack support bracket & Fabricated in house & $\mathrm{N} / \mathrm{A}$ & 2 \\
\hline 51 & Sample target right angle bracket & Fabricated in house & $\mathrm{N} / \mathrm{A}$ & 1 \\
\hline 52 & Sample plate Teflon insulator & Fabricated in house & $\mathrm{N} / \mathrm{A}$ & 1 \\
\hline 53 & Computer shelf & Fabricated in house & $\mathrm{N} / \mathrm{A}$ & 1 \\
\hline 54 & Extended capillary & Fabricated in house & $\mathrm{N} / \mathrm{A}$ & 1 \\
\hline 55 & Laser spacing block & Fabricated in house & $\mathrm{N} / \mathrm{A}$ & 1 \\
\hline
\end{tabular}

The manually actuated pulsed nitrogen laser (337 $\mathrm{nm}$ ) was replaced by the Explorer laser system (part no. 1), a Q-switched diode pumped solid-state ultraviolet laser $(349 \mathrm{~nm}$ ) with first pulse suppression, precise internally measured laser power $(0-120 \mu \mathrm{J})$ and repetition rate control $(0-5000 \mathrm{~Hz})$ using the supplied soft- ware (Spectra-Physics, L-Win). The laser power, repetition rate and translation stage velocity control (0-5 $\mathrm{mm} / \mathrm{s}$ ) are invaluable for applications to various samples, surfaces and desorption conditions; preventing damage to solid substrate and depletion of analyte during analysis. The high-resolution CCD camera 
Table 2. Description of parts fabricated in-house

4616 in. $\times 16$ in. $\times 3 / 8$ in. thickness aluminum (thickness may be reduced to $1 / 4 \mathrm{in}$.), drilled and tapped $1 / 4 \times 20$ (1" on center)

478 in. $\times 1 / 2$ in. thickness aluminum, two piece clamp for Monozoom lens support

482 in. $\times 1 / 2$ in. $\times 1 / 4$ in. thickness Teflon; cut-out to receive a stainless steel union, threaded tube inserted across width to attach aluminum retainer and electrical contact for ESI voltage

$491 \frac{1}{4}$ in. $\times 1 / 8$ in. $\times 1 / 32$ in. thickness stainless steel with custom bend for electrical contact with sample target

5016 in. $\times 2 \frac{1}{2}$ in. (1 $1 \frac{1}{2}$ in. along component attachment region) $\times 1 / 4$ in. thickness aluminum, slots at each end for attachment to support frame (part no. 20)

513 in. length $\times 2 \frac{1}{2}$ in. height, $1 / 4$ in. thickness aluminum, (2) vertical slots cut in short side for attachment to $X Y Z$ stage, (2) clear holes (no. 8) in long side for Teflon target insulator attachment

$52 \frac{1}{1} / 2$ in. $\times 2 \frac{1}{2}$ in. $\times 1 / 4$ in. thickness Teflon with (2) small stainless steel posts to accommodate the sample target and (2) holes drilled and tapped 8/32 in. from bottom to attach to sample target bracket (part no. 51)

$531 / 4$ in. thickness aluminum, cut to fit across upper cross members of support frame (part no. 20)

542 in. extended stainless steel capillary with lug to fit LTO atmospheric pressure interface

$557 \frac{1}{2}$ in. $\times 3 \frac{3}{4}$ in. $\times 1 \frac{1}{2}$ in. aluminum block including $1 / 2$ in. slots on each end for $1 / 4 \times 20$ screw attachment to the breadboard (part no. 19)

(parts no. 32-34) was connected using the WinTV PCI tuner (part no. 35) to the laptop computer and monitor (parts no. 30,31) enabling real time on screen visualization and recording of the sample spot and tracking of the laser spot on target during laser ablation, which is particularly useful for analysis of small sample spots as well as tissue sections for imaging.

The XYZ stage (parts no. 2-5, 38, 49, 51, 52), second stage laser beam positioning mirror (part no. 18, mounted in the upper portion of the periscope assembly parts no. 21, 11,8), focusing lens assembly (parts no. $8,9,11,13,14,16,17)$, ESI emitter assembly (parts no. $8,9,12,12,15,40-44,48)$, and CCD camera assembly (parts no. 8, 9, 10, 13, 32-34, 47) were all mounted onto the custom fabricated breadboard (part no. 46). Schematics of the desorption and ionization region with a description of each subassembly are shown in Figures 2 and 3. A clear hole drilled in the breadboard (part no. 46) allows the passage of the laser beam from the first stage directional mirror (parts no. 18, 21, 22) mounted on the main breadboard work surface (part no. 19) to the second stage directional mirror (parts no. 8, 11, 18, 21) mounted on the custom breadboard (part no. 46). The breadboard (part no. 46) with all mounted equipment was then mounted onto the vibrationally isolated main breadboard (part no. 19) using 4 in. offset posts (part no. 23). The laser (part no. 1) mounted to a custom fabricated spacing block (part no. 55), first stage laser beam positioning mirror (part no. 18 mounted in lower portion of the periscope assembly, part no. 21, attached to a 4 inch post, part no. 22), syringe pump (part no. 28), light source (part no. 29) and monitor (part no. 31) were mounted on the main breadboard (part no. 19). The field of the main breadboard (part no. 19) and custom breadboard (part no. 46) were fabricated with tapped holes $(1 / 4 \times 20)$ on one inch center; a supply of appropriate fasteners is required to attach various components to the breadboards.

The high voltage power supply (part no. 27) and motion controller (part no. 6) were mounted to the support frame (part no. 20) using custom fabricated rack mounting brackets (part no. 50). The high voltage power supply (part no. 27) was attached to the sample target high voltage clip (part no. 49) using $5 \mathrm{kV}$ insulated wire (part no. 38) for contact with the stainless steel sample target (part no. 36) mounted on the Teflon insulator (part no. 52). The keyboard, mouse, and

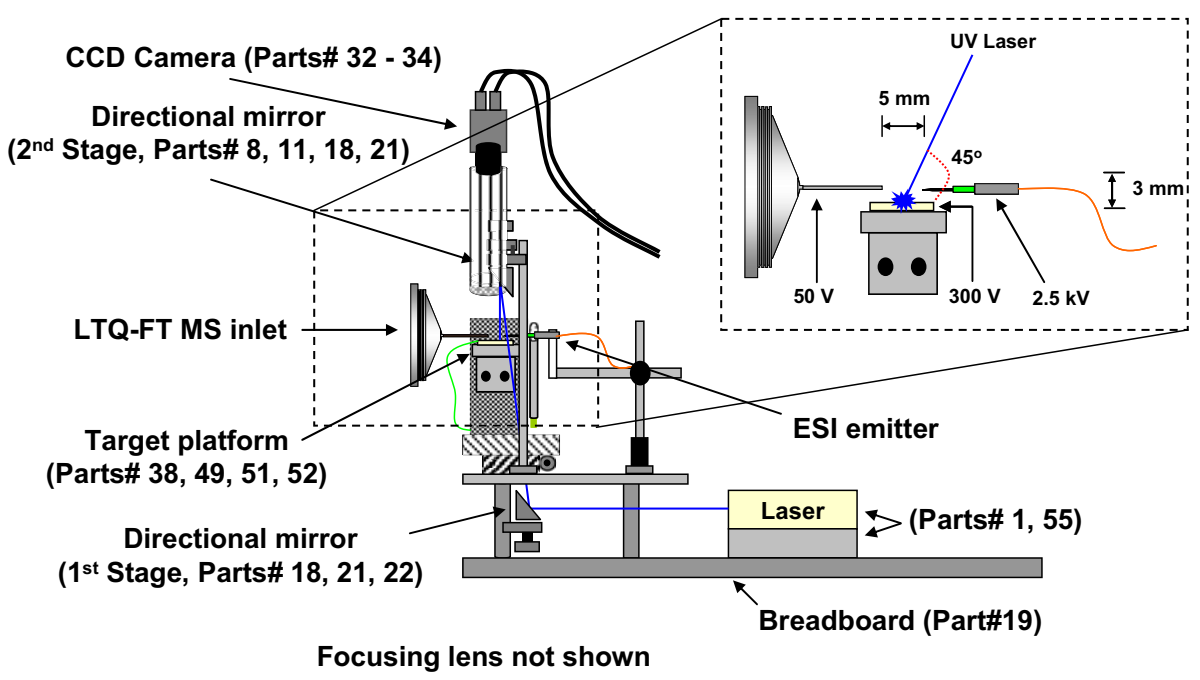

Figure 2. Side view schematic of the ionization region of the MALDESI source with the numbers corresponding to the parts listed in Table 1. 


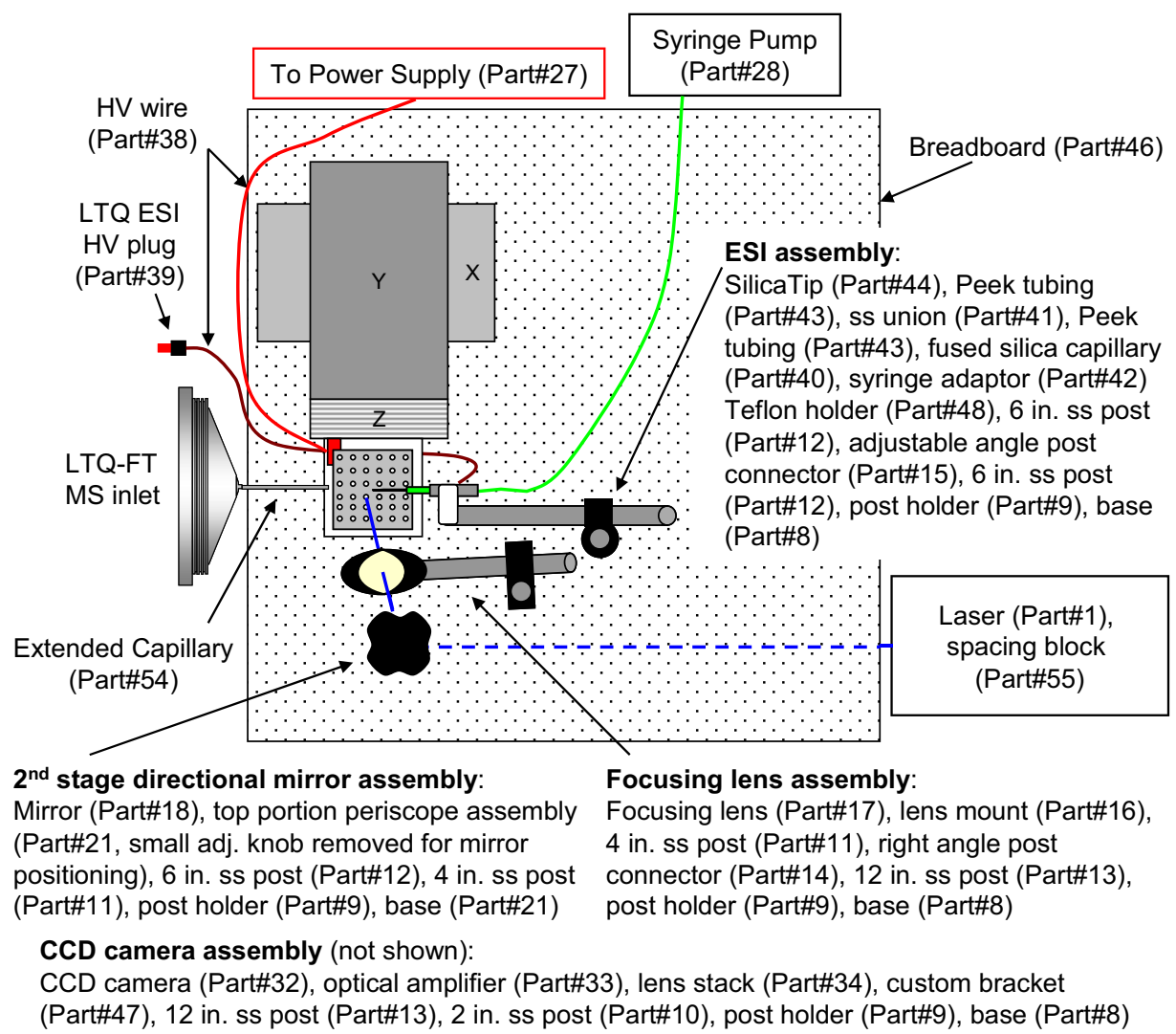

Figure 3. Top view schematic of the ionization region with a listing of the parts for each sub-assembly.

laptop computer (part no. 30) were placed onto a custom fabricated shelf (part no. 53) situated on the upper cross beams of the support frame (part no. 20). Power management was provided using two 6-plug power strips (part no. 26) installed on the inside of the vertical supports on the rear of the support frame (part no. 20). Before assembly, casters (parts no. 24, 25) were installed to replace the existing adjustable feet on the support frame for mobility. The versatility of this ionization source platform allows for interchangeability of the source between instruments as well as installation of new components onto the existing platform.

\section{Desorption and Ionization Source Versatility}

The high stability ionization source platform may be implemented using various desorption and ionization techniques for application specific analysis. Existing ionization sources may be installed onto the platform due to the inherent versatility of the breadboard for roll-up accessibility. Analyte desorption may be induced by one of a number of regimes, including laser desorption as in MALDESI, laserinduced acoustic desorption (LIAD) [20], heated nitrogen gas amplification, sequencing, and annotation of plastomes (ASAP) [21], and impact of high velocity charged droplets as in DESI [6], followed by a number of post-desorption ionization methods including atmospheric pressure photo ionization (APPI) [22], atmospheric pressure chemical ionization (APCI) [23], and electrospray ionization (ESI) [24]. In addition to the hybrid ionization sources listed above, this platform is amenable to basic electrospray ionization [24] and atmospheric pressure matrix-assisted laser desorption ionization [25].

\section{Results and Discussion}

\section{Explorer Laser Beam Characterization}

The laser beam spot size was measured at a laser power of $112 \mu \mathrm{J}$ (measured internally) using a gold coated quartz crystal microbalance electrode as the laser target. A photo of the QCM electrode following laser ablation is shown in Figure $4 \mathrm{~b}$, with an expanded view of a single ablation crater shown in Figure $4 \mathrm{c}$. In these experiments, the thin gold top layer $(1000 \AA)$ was removed exposing the chromium base layer with some re-deposition along the perimeter of the ablated crater. The elliptical laser beam spot size $(60 \mu \mathrm{m} \times 80 \mu \mathrm{m})$ was determined by measuring the actual diameter of the ablation craters using a Tencor Alpha Step profilometer. A representative scan plot is shown in Figure 4a. 
(a)

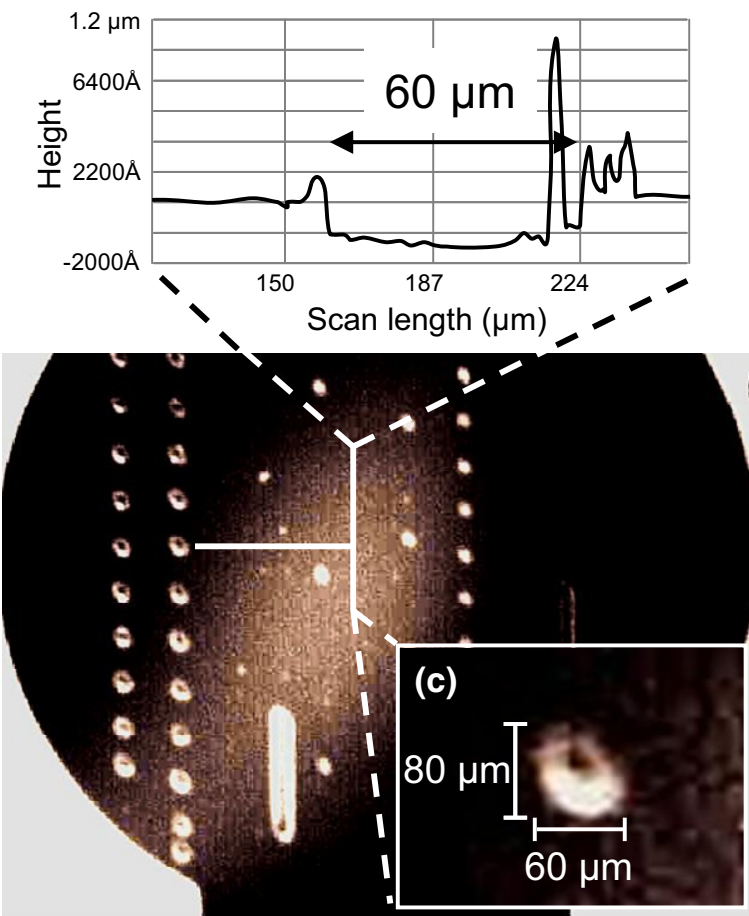

(b)

Figure 4. (a) Profilometer scan plot across the width $(60 \mu \mathrm{m})$ of the laser ablation crater in the gold QCM electrode. (b) Photograph of the QCM electrode after laser desorption. (c) Expanded view of an elliptical ablation crater, the diameters $(60 \mu \mathrm{m} \times 80$ $\mu \mathrm{m}$ ) were measured for multiple ablation craters across the QCM electrode.

\section{MALDESI-LTQ-FT-ICR of Peptides and Proteins}

MALDESI-FT-ICR mass spectra of peptides and proteins $(1-8.6 \mathrm{kDa})$ including bradykinin, angiotensin I, melittin, glucagon, and ubiquitin each mixed with organic matrix have been shown previously [12, 13]. Comparable data were obtained using the new source; representative MALDESI-FT-ICR mass spectra of bradykinin and melittin both mixed with DHB are included in Supplemental Material (Figure S3). Lysozyme and myoglobin (not shown previously) were each mixed 1:1 (vol:vol) with DHB, $0.8 \mu \mathrm{L}$ was deposited onto the sample target and actively dried [19]. The ESI solution flow-rate was set to $400 \mathrm{~nL} / \mathrm{min}$ and stable electrospray was obtained. The motion controller was preprogrammed to raster the sample surface under the laser beam as illustrated in the Supplemental Material (Figure S2). The laser was actuated using computer control at a laser power of $50 \mu \mathrm{J}$ (measured internally) and repetition rate of $10 \mathrm{~Hz}$ and the motion program initiated. Multiply-charged ions were generated and detected for each peptide and protein; demonstrating a molecular weight range from 1 to $17 \mathrm{kDa}$ using this source. Representative MALDESI-FT-ICR mass spectra of myoglobin and lysozyme from this experiment are shown in Figure 5, with an observed resolving power of $\sim 40,000$.
The amount of material ablated during analysis was calculated using the amount of material spotted $(\sim 80$ pmol), collection time (200 ms), laser repetition rate (10 $\mathrm{Hz}, 2$ shots per collection), area of the laser spot (3846 $\left.\mu \mathrm{m}^{2}\right)$, and the area of the dried spot $\left(\mathrm{A}=3.14 \mathrm{~mm}^{2}\right) ; 196$ fmol were removed per spectrum, assuming uniform distribution of analyte and complete removal at each laser shot. The development and implementation of molecular transport devices such as the air amplifier [26, 27], air ejector [28], and remote analyte sampling, transport, and ionization relay (RASTIR) [29], which enable the efficient transport of ions into the mass spectrometer have been investigated and may prove important to increasing sensitivity.

\section{Liquid Drop Sample Analysis}

Liquid drop analysis of $0.8 \mu \mathrm{L}$ droplets of $200 \mu \mathrm{M}$ ubiquitin and myoglobin mixed 1:1 (vol:vol) with DHB $(150 \mathrm{mg} / \mathrm{mL})$ and deposited onto the sample target, biased at $300 \mathrm{~V}$, for immediate analysis is demonstrated using MALDESI with ESI post-ionization. Liquid drop laser desorption analysis with ESI postionization has been demonstrated previously [11, 30]. The ESI emitter was biased at $2.8 \mathrm{kV}$ to electrospray $50 \%$ acetonitrile in water at a flow rate of $400 \mathrm{~nL} / \mathrm{min}$. The liquid sample was continuously irradiated using the Explorer laser without moving the sample target, yielding relatively constant ion abundance over the lifetime of the droplet $(\sim 30 \mathrm{~s})$. liq-MALDESI-FT-ICR mass spectra of myoglobin and ubiquitin with ESI post-ionization are shown in Supplemental Material (Figure S4A and B), respectively.

\section{Conclusions}

The MALDESI ionization source described herein couples high stability with precision motion and laser control. This design enables high mass resolving power analysis of biological molecules including intact and top-down characterization in addition to facilitating potential imaging applications.

The mobile design provides a stable analytical platform which may be used to implement a number of desorption regimes including laser desorption (e.g., MALDESI), high velocity solvent droplets (e.g., DESI), a stream of heated nitrogen gas (e.g., ASAP), and postdesorption ionization using electrospray ionization (ESI), chemical (e.g., APCI), and photon ionization (e.g., APPI) for analysis of various types and classes of molecules on multiple MS platforms. The modular configuration of the MALDESI ionization source can facilitate the substitution of parts as necessary for specific applications or budgeting constraints. Furthermore, an IR laser could be mounted to the laser table breadboard for infrared laser MALDESI applications (IR-LDESI) [14, 15]. 


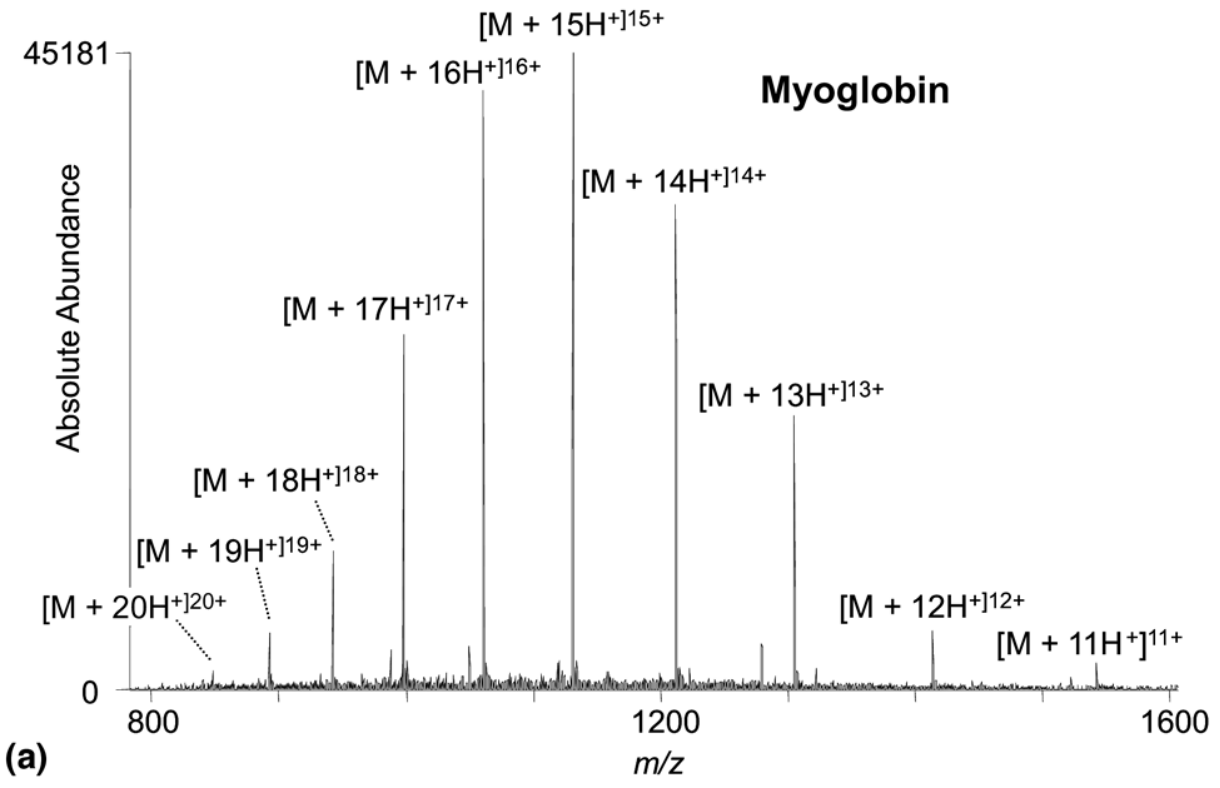

(a)

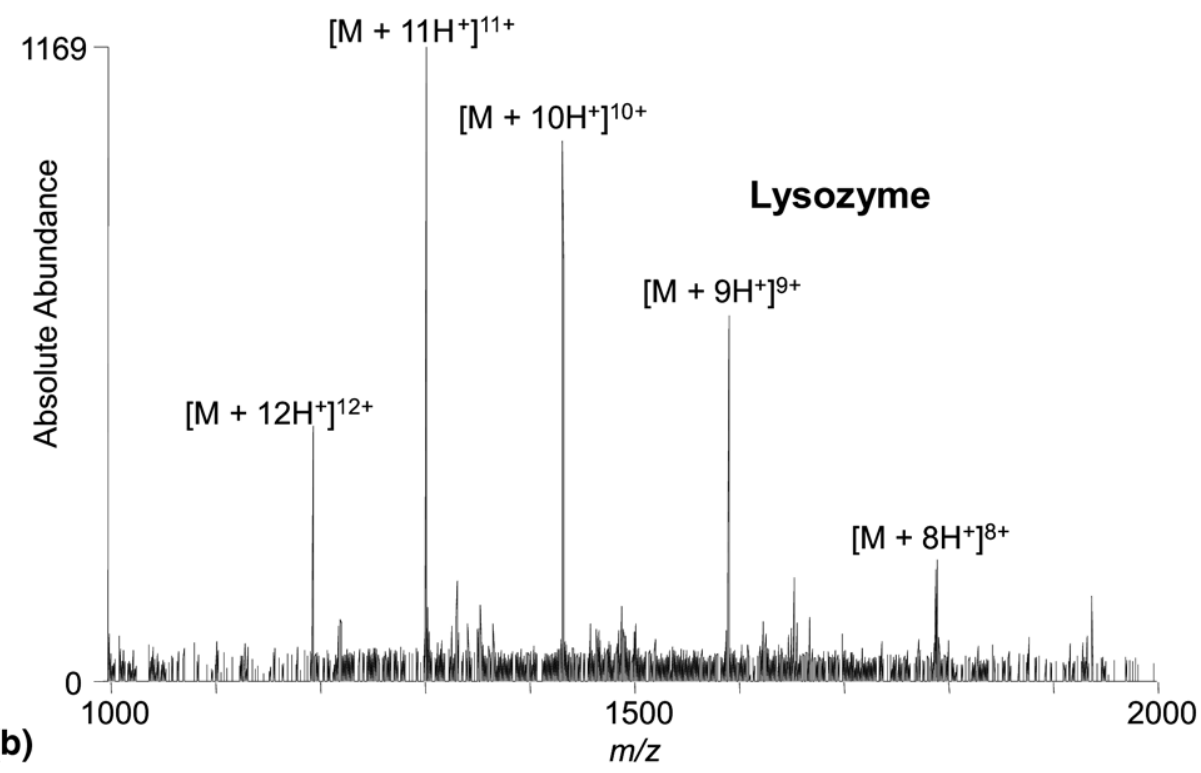

Figure 5. MALDESI-FT-ICR mass spectra of $0.8 \mu \mathrm{L}$ actively dried spot of $200 \mu \mathrm{M}$ (a) myoglobin (16.9 $\mathrm{kDa})$ and (b) lysozyme C (14.3 kDa) mixed 1:1 (vol:vol) with $150 \mathrm{mg} / \mathrm{mL}$ DHB.

\section{Acknowledgments}

The authors thank Dr. John A. Mclean of Vanderbilt University for assistance in acquiring the Explorer laser system, Dr. Fred Stevie in the Analytical Instrumentation Facility at North Carolina State University for assistance with the profilometer measurements, and the machine shop personnel in the College of Physical and Mathematical Sciences at North Carolina State University for their assistance with the MALDESI source construction. The authors gratefully acknowledge financial support received from the National Cancer Institute, National Institutes of Health (R33 CA105295), the W. M. Keck Foundation, the William R. Kenan Jr. Fund for Engineering, Technology and Science, and North Carolina State University.

\section{References}

1. Kolaitis, L.; Lubman, D. M. Detection of Nonvolatile Species by Laser Desorption Atmospheric-Pressure Mass-Spectrometry. Anal. Chem. 1986, 58(11), 2137-2142.
2. Coon, J. J.; McHale, K. J.; Harrison, W. W. Atmospheric Pressure Laser Desorption/Chemical Ionization Mass Spectrometry: A New Ionization Method Based on Existing Themes. Rapid Commun. Mass Spectrom. 2002, 16(7), 681-685.

3. Chang, D. Y.; Lee, C. C.; Shiea, J. Detecting Large Biomolecules from High-Salt Solutions by Fused-Droplet Electrospray Ionization Mass Spectrometry. Anal. Chem. 2002, 74(11), 2465-2469.

4. Chen, H. W.; Venter, A.; Cooks, R. G. Extractive Electrospray Ionization for Direct Analysis of Undiluted Urine, Milk. and Other Complex Mixtures Without Sample Preparation. Chem. Commun. 2006, 19, 2042 2044.

5. Cody, R. B.; Laramee, J. A.; Durst, H. D. Versatile New Ion Source for the Analysis of Materials in Open Air Under Ambient Conditions. Anal. Chem. 2005, 77(8), 2297-2302.

6. Takats, Z.; Wiseman, J. M.; Gologan, B.; Cooks, R. G. Mass Spectrometry Sampling Under Ambient Conditions with Desorption Electrospray Ionization. Science 2004, 306(5695), 471-473.

7. Shiea, J.; Huang, M. Z.; Hsu, H. J.; Lee, C. Y.; Yuan, C. H.; Beech, I.; Sunner, J. Electrospray-Assisted Laser Desorption/Ionization Mass Spectrometry for Direct Ambient Analysis of Solids. Rapid Commun. Mass Spectrom. 2005, 19(24), 3701-3704.

8. Huang, M. Z.; Hsu, H. J.; Lee, J. Y.; Jeng, J.; Shiea, J. Direct Protein Detection from Biological Media through Electrospray-Assisted Laser 
Desorption Ionization/Mass Spectrometry. J. Proteome Res. 2006, 5(5), 1107-1116.

9. Huang, M. Z.; Hsu, H. J.; Wu, C. I.; Lin, S. Y.; Ma, Y. L.; Cheng, T. L.; Shiea, J. Characterization of the Chemical Components on the Surface of Different Solids with Electrospray-Assisted Laser Desorption Ionization Mass Spectrometry. Rapid Commun. Mass Spectrom. 2007, 21(11), 17671775.

10. Lin, S. Y.; Huang, M. Z.; Chang, H. C.; Shiea, J. Using ElectrosprayAssisted Laser Desorption/Ionization Mass Spectrometry to Characterize Organic Compounds Separated on Thin-Layer Chromatography Plates. Anal. Chem. 2007, 79(22), 8789-8795.

11. Peng, I. X.; Shiea, J.; Loo, R. R. O.; Loo, J. A. Electrospray-Assisted Laser Desorption/Ionization and Tandem Mass Spectrometry of Peptides and Proteins. Rapid Commun. Mass Spectrom. 2007, 21(16), 2541-2546.

12. Sampson, J. S.; Hawkridge, A. M.; Muddiman, D. C. Generation and Detection of Multiply-Charged Peptides and Proteins by MatrixAssisted Laser Desorption Electrospray Ionization (MALDESI) Fourier Transform Ion Cyclotron Resonance Mass Spectrometry. J. Am. Soc. Mass Spectrom. 2006, 17(12), 1712-1716.

13. Sampson, J. S.; Hawkridge, A. M.; Muddiman, D. C. Direct Characterization of Intact Polypeptides by Matrix-Assisted Laser Desorption Electrospray Ionization Quadrupole Fourier Transform Ion Cyclotron Resonance Mass Spectrometry. Rapid Commun. Mass Spectrom. 2007, 21(7), 1150-1154.

14. Nemes, P.; Vertes, A. Laser Ablation Electrospray Ionization for Atmospheric Pressure in Vivo and Imaging Mass Spectrometry. Anal. Chem. 2007, 79(21), 8098-8106.

15. Rezenom, Y. H.; Dong, J.; Murray, K. K. Infrared Laser-Assisted Desorption Electrospray Ionization Mass Spectrometry. Analyst 2008, 133(2), 226-232.

16. Marshall, A. G.; Guan, S. H. Advantages of High Magnetic Field for Fourier Transform Ion Cyclotron Resonance Mass Dpectrometry. Rapid Commun. Mass Spectrom. 1996, 10(14), 1819-1823.

17. Kelleher, N. L.; Lin, H. Y.; Valaskovic, G. A.; Aaserud, D. J.; Fridriksson, E. K.; McLafferty, F. W. Top-Down Versus Bottom-Up Protein Characterization by Tandem High-Resolution Mass Spectrometry. J. Am. Chem. Soc. 1999, 121(4), 806-812.

18. Kelleher, N. L. Top-Down Proteomics. Anal. Chem. 2004, 76(11), 196A203A.

19. Williams, T. I.; Saggese, D. A.; Wilcox, R. J.; Martin, J. D.; Muddiman, D. C. Effect of Matrix Crystal Structure on Ion Abundance of Carbohy- drates by Matrix-Assisted Laser Desorption/Ionization Fourier Transform Ion Cyclotron Resonance Mass Spectrometry. Rapid Commun. Mass Spectrom. 2007, 21(5), 807-811.

20. Golovlev, V. V.; Allman, S. L.; Garrett, W. R.; Taranenko, N. I.; Chen, C. H. Laser-Induced Acoustic Desorption. Int. J. Mass Spectrom. 1997, $169,69-78$.

21. McEwen, C. N.; McKay, R. G.; Larsen, B. S. Analysis of Solids, Liquids, and Biological Tissues Using Solids Probe Introduction at Atmospheric Pressure on Commercial LC/MS Instruments. Anal. Chem. 2005, 77(23), $7826-7831$.

22. Robb, D. B.; Covey, T. R.; Bruins, A. P. Atmospheric Pressure Photoionization: An Ionization Method for Liquid Chromatography-Mass Spectrometry. Anal. Chem. 2000, 72(15), 3653-3659.

23. Shahin, M. M. Mass-Spectrometric Studies of Corona Discharges in Air at Atmospheric Pressures. J. Chem. Physics 1966, 45(7), 2600.

24. Fenn, J. B.; Mann, M.; Meng, C. K.; Wong, S. F.; Whitehouse, C. M Electrospray Ionization for Mass-Spectrometry of Large Biomolecules. Science 1989, 246(4926), 64-71.

25. Laiko, V. V.; Baldwin, M. A.; Burlingame, A. L. Atmospheric Pressure Matrix Assisted Laser Desorption/Ionization Mass Spectrometry. Anal. Chem. 2000, 72(4), 652-657.

26. Zhou, L.; Yue, B. F.; Dearden, D. V.; Lee, E. D.; Rockwood, A. L.; Lee, M. L. Incorporation of a Venturi Device in Electrospray Ionization. Anal. Chem. 2003, 75(21), 5978-5983.

27. Dixon, R. B.; Muddiman, D. C.; Hawkridge, A. M.; Fedorov, A. G Probing the Mechanisms of an Air Amplifier Using a LTQ-FT-ICR-MS and Fluorescence Spectroscopy. J. Am. Soc. Mass Spectrom. 2007, 18(11), 1909-1913.

28. Dixon, R. B.; Bereman, M. S.; Muddiman, D. C.; Hawkridge, A. M. Remote Mass Spectrometric Sampling of Electrospray- and Desorption Electrospray-Generated Ions Using an Air Ejector. J. Am. Soc. Mass Spectrom. 2007, 18(10), 1844-1847.

29. Dixon, R. B.; Sampson, J. S.; Hawkridge, A. M.; Muddiman, D. C. Novel Ambient Aerodynamic Ionization Source for Remote Analyte Sampling and Mass Spectrometric Analysis. Anal. Chem. 2008, 80(13), 5266-5271.

30. Sampson, J. S.; Hawkridge, A. M.; Muddiman, D. C. Development and Characterization of a New Ionization Technique for Analysis of Biological Macromolecules: Liquid Matrix-Assisted Laser Desorption Electrospray Ionization. Anal. Chem. 2008, in press. 